\title{
Assessment of College of Nursing Students' Knowledge about Autism
}

\section{Disorder}

\section{Mohanned Khaleel Abdullah*}

\section{ABSTRACT}

Background and aim: Knowledge and awareness about childhood autism is something essential for students at college of nursing. Nursing staff based on the provision of health care for children with autism should have knowledge of the way autistic people see the world and therefore have the ability to understand and provide therapeutic assistance to them. This study assesses the knowledge of undergraduate nursing students at College of Nursing University of Mosul about Autism.

Materials and method: The sample of the study consists of 110 undergraduate students in College of Nursing / University of Mosul. They were chosen randomly. They are (32) males and (78) females. A questionnaire presented by the researchers after comprehensive review.

Results: The results of the study showed that a high percentage (85.5\%) of the students stated that they didn't study about this subject. It also showed that $(87.3 \%)$ of the participants answered that parents' careless leads to Autistic disorder.

Conclusion: Depending on the results, the study showed that there is no care about this subject in studying curriculums of the college. Most of the sample of this study don't know if there are any health care centers in Mosul city for Autistic disorder

Recommendations: More attention should be paid about this subject in studying curriculums at the college. Then awareness about Autistics disorder need to be improved among students and parents.

Keywords: Assessment, Autism Disorder, Nursing Students, Knowledge about Autism.

\section{INTRODUCTION}

Today, the world of autism is ever changing. Increases in public awareness, research on finding the cause(s) of autism, and development and implementation of effective early interventions surround us. These changes have led to a significant problem that the autism community is realizing. VanBergeijk, Klin, and Volkmar (2008) state that the CDC (Center for Disease Control) estimates that 1 in 166 children in the United States (500,000 Americans) have been diagnosed with ASD (autism spectrum disorder).

The Centers for Disease Control and Prevention (CDC) estimates that the prevalence of autism reaches one child per 68 children in the United States. One child includes 42 children and one child for 189 girls.(The National Autistic Society, 2007).

An estimated one child in every 160 children in the world suffers from autism spectrum disorder. These estimates represent an average number and the reported prevalence varies widely among studies. However, some well-controlled studies reported much higher rates. The prevalence of autism spectrum disorders is still unknown in several low- and middle-income countries. According to epidemiological studies conducted over the past 50 years, the prevalence of autism spectrum disorders appears to be increasing at the global level. This visible increase in prevalence can be explained in several ways, in particular by enhancing awareness, expanding diagnostic standards, improving diagnostic tools and improving reporting(WHO,2017)

Autism is characterized by severe and pervasive impairments in several important areas of development: reciprocal social interaction and communication as well as behavior, and imagination. In order to be diagnosed with autism, the behavioral symptoms in all of the above-named areas must be present by age 3 . Even if the parents often notice that something is wrong during infancy, it is very difficult to diagnose autism before the age of eighteen months. This is because the behavioral symptoms used to establish the diagnosis have not clearly emerged developmentally until that age (Zander, 2005) .

Autism is a neuro-developmental disorder defined behaviorally by a triad of impairments (Mandelbaum et. al., 2006). The triad of impairments are: social development, communication, and repetitive behavior (BaronCohen, 2005). Autism is differentiated from mental retardation, another neuro-developmental condition, by the distinct impairment of social and communication development. Autism is categorized in Pervasive Developmental

* Assist. Lecturer / College of Nursing / University of Mosul / mohannedkhalil2016@yahoo.com 
Disorders (Bregman, 2005).

Scientists have detected differences in the pathway of brain signals, causing autism spectrum disorders to be more common among males.One interesting aspect of autism is that it mostly affects males, while its effect on females is lower, at 4 males per girl. Autistic children are commonly detected before age of 3 years (Taylor, 2006). Parents experience many feelings that begin with frustration and anxiety. These feelings persist until the transition to the stage of seeking appropriate solutions and a sense of responsibility. There are several factors that effect on how parents react and how much they feel, and which factors The severity of autism and whether accompanied by mental disability and severity of disability.

Parents' feelings of pain and sadness may turn their child's situation into a feeling of depression and misery This may develop into a sense of pessimism and loss of self-confidence as the effect may extend to Inability to sleep and loss of appetite for food, then parents must use and ask for help from them who help them out of their ordeal. Adams et. al. (2004)

Young children have difficulties when asked to share their experiences with others. When reading a story, for example, they cannot point their finger at the pictures in the book. This social skill, which develops at a very young age, is essential for the development of language and social skills at a later stage of growth. As children grow into adulthood, some of them may become more capable and willing to mix and integrate into the surrounding social environment, and they may exhibit behavioral disorders that are less than those that characterize autism, and some even succeed in living a normal life or lifestyle Close to ordinary and natural. On the other hand, others continue to have difficulties in language skills and in social relationships, so that their attainment only increases their behavioral problems worse and worse. (Gillberg and Coleman, 2000; Taylor, 2006).

A number of children are slow to learn new information and skills. Others enjoy natural intelligence, or even higher than ordinary people. These children learn quickly, but they have communication problems, in the application of things they have learned in their daily lives and in adapting themselves to changing social situations and situations. (Autism Society of America, 2007).
A very small proportion of children with autism are autistic intellectuals with unique and exceptional skills, particularly concentrated in a particular area such as art, mathematics or music. (Piek and Dyck ,2004).

Because autism ranges from so many degrees of severity to the severity of the disease, autism may be a complex and complex task. There is no specific medical examination to detect a state of autism. (Bregman, 2005)

Instead, the formal assessment of autism includes a pediatrician's examination, a conversation with parents about the child's social skills, his or her language abilities, behavior, and how and how these factors change over time. Adams et. al. (2004)

In order to diagnose autism symptoms, the doctor may request that the child undergo several tests and tests aimed at assessing his or her verbal and linguistic abilities and examining some psychological aspects. (Gillberg and Coleman, 2000)

Although primary autism symptoms often appear before 18 months of age, in some cases, when a child is only 2 or 3 years old, the final diagnosis is only when a developmental defect occurs, delaying the acquisition of language skills, Or imbalance in social relationships, which are obvious at this stage of life. Stahmer et. al. (2005)

Early diagnosis is very important, since early intervention, as much as possible, especially before reaching the age of three years, is a very important element in achieving the best prospects and opportunities for a better situation.

used focus groups to investigate techniques employed in community early intervention programs in California. These techniques are: Lovass Technique, Applied Behavior Analysis, Sensory Integration, Peer Mediated Interventions, PECS/Sign Language, Video Modeling Programs, Social Stories and Parent Training Programs.

\section{MATERIALS AND METHOD}

A descriptive study is designed to assess the knowledge of undergraduate students of Nursing College about Autistic Disorder started from $\left(10^{\text {th }}\right.$ to $22^{\text {th }}$ of November, 2015. The study was conducted in College of Nursing / University of Mosul (Kirkuk Location). The 
sample of the study consists of 110 undergraduate students in College of Nursing / University of Mosul. They are (32) males and (78) females. This sample is chosen randomly. A questionnaire presented by the researchers after comprehensive review. This instrument is consisting of 2 parts. Part one Demographic data sheet of the study sample. This part is concerned with the determination of the demographic characteristics of the sample of the study by designing a data sheet which includes main items: Gender and Year of study (stage). And Part two - Student's knowledge concerning to Autistics Disorder. This Part of the questionnaire includes (15) questions about the student's knowledge regarding to Autistics Disorder. The answer of any question is either "Yes" or "No".

The face validity of the study tools was verified through a panel of (12) experts of different specialties related to the field of the present study. Reliability refers to the consistency of a particular method in measuring

\section{RESULTS}

or observing the same phenomenon ( Parahoo, 2006). For testing the reliability of the questioners, a pilot study was conducted in College of Nursing / University of Mosul: Eight students were involved in a pilot study from, 2 from each stage. It was carried out for the period from $12^{\text {th }}$ December 2013 to $22^{\text {nd }}$ December 2013, and by Cronbach Coefficient Correlation to compute the reliability, it was $\mathrm{r}=$ (0.85). Data were collected through the use of à structure questionnaire interview technique for the period extending from ( $10^{\text {th }}$ February) 2014 to $\left(10^{\text {th }}\right.$ March) 2014 . A personal permission was obtained from the students to participate in the study. Data are prepared, organized and entered into a computer file; Different statistical methods were used to analyze the data in this study. Statistical processing was conducted by the use of SPSS version 17 and Minitab. Chisquare test was used as the test of significance to determine the presence of association between variables; $\mathrm{P}<0.05$ was considered significant.

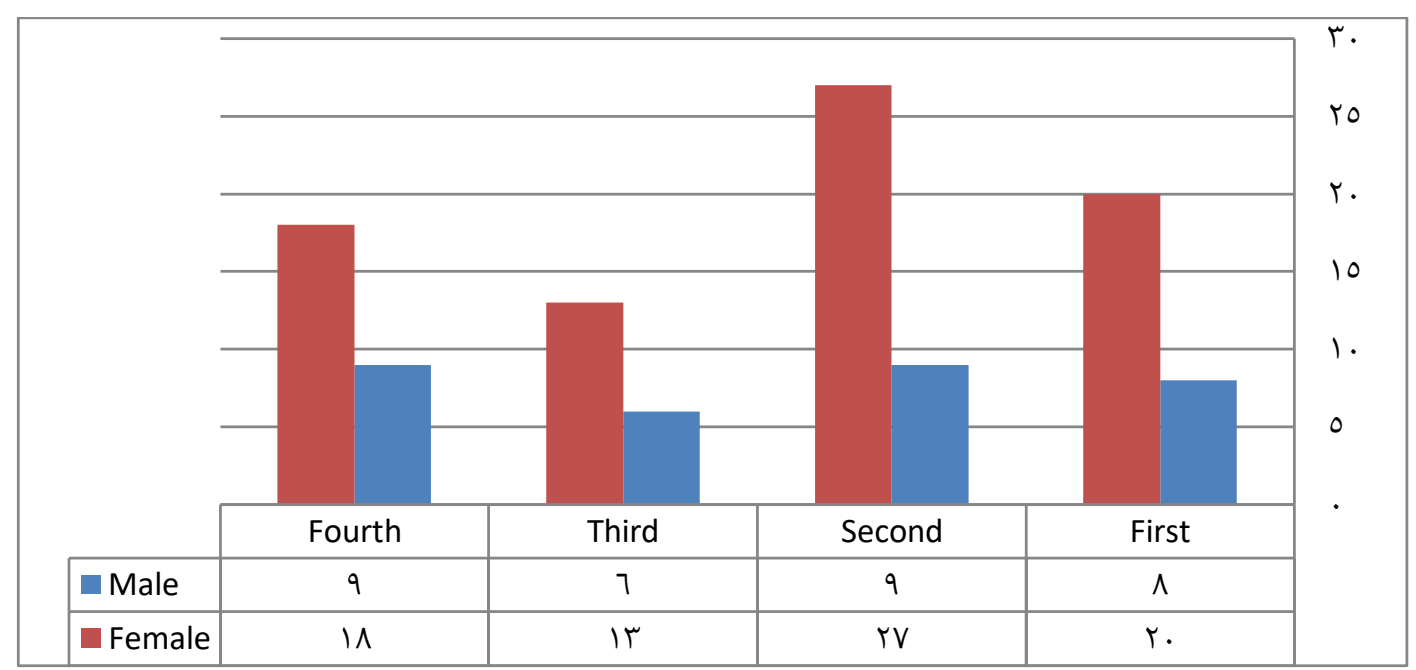

Figure :-1- Distribution of the Demographic Characteristic of the Study Sample (No=110).

Table (1) Nursing Students Knowledge about autistic disorders (No=110).

\begin{tabular}{|c|c|c|c|c|c|}
\hline & \multirow{2}{*}{ Statement } & \multicolumn{2}{|c|}{ Yes } & \multicolumn{2}{|c|}{ No } \\
\hline & & $\mathbf{F}$ & $\%$ & $\mathbf{F}$ & $\%$ \\
\hline $1-$ & $\begin{array}{l}\text { As a student in College of Nursing, did you ever study } \\
\text { about Autistic disorder? }\end{array}$ & 16 & 14.5 & 94 & 85.5 \\
\hline $2-$ & $\begin{array}{l}\text { Do you have a family member or close friend with } \\
\text { autism? }\end{array}$ & 13 & 11.8 & 97 & 88.2 \\
\hline $3-$ & Does Autism occur because of genetics factors? & 39 & 35.5 & 71 & 64.5 \\
\hline $4-$ & Autism is a neuro-developmental disorder. & 84 & 76.4 & 26 & 23.6 \\
\hline $5-$ & $\begin{array}{l}\text { Do you think that parents' careless leads to Autistic } \\
\text { disorder? }\end{array}$ & 96 & 87.3 & 14 & 12.7 \\
\hline $6-$ & Does Autism occur because of some vaccines? & 20 & 18.2 & 90 & 81.8 \\
\hline $7-$ & $\begin{array}{l}\text { Autism could be associated with abnormal eating, } \\
\text { drinking and sleeping habits. }\end{array}$ & 86 & 78.2 & 24 & 21.8 \\
\hline $8-$ & Autism could be associated with anger and crying for & 90 & 81.8 & 20 & 18.2 \\
\hline
\end{tabular}




\begin{tabular}{|c|c|c|c|c|c|}
\hline & unknown reasons. & & & & \\
\hline 9- & $\begin{array}{l}\text { Autism could be associated with low activity and } \\
\text { concerns, and repeated actions. }\end{array}$ & 88 & 80.0 & 22 & 20.0 \\
\hline $10-$ & Autism could be associated with low communication & 106 & 96.4 & 4 & 3.6 \\
\hline $11-$ & $\begin{array}{l}\text { Autism could be associated with no response to } \\
\text { traditional teaching methods. }\end{array}$ & 67 & 60.9 & 43 & 39.1 \\
\hline $12-$ & $\begin{array}{l}\text { Autistic characteristics appear before the third years } \\
\text { age. }\end{array}$ & 64 & 58.2 & 46 & 41.8 \\
\hline $13-$ & $\begin{array}{l}\text { Late in talking, playing and communication are } \\
\text { diagnoses of Autistic disorders. }\end{array}$ & 85 & 77.3 & 25 & 22.7 \\
\hline $14-$ & $\begin{array}{l}\text { Are there any health care centers in your city for } \\
\text { autism? }\end{array}$ & 52 & 47.3 & 58 & 52.7 \\
\hline $15-$ & $\begin{array}{l}\text { Are drugs, diet, vitamins and psychological therapy, } \\
\text { the best treatment for Autistic disorder? }\end{array}$ & 74 & 67.3 & 36 & 32.7 \\
\hline
\end{tabular}

Chi-Sq. $=492.186, \mathrm{DF}=14, \mathrm{P}$-Value $=0.000$

Table (2) Frequencies distribution for the study sample in respect to their gender $(\mathrm{No}=110)$.

\begin{tabular}{|c|c|c|c|c|}
\hline & \multicolumn{2}{|c|}{ Yes } & \multicolumn{2}{|c|}{ No } \\
\hline & $\mathbf{F}$ & $\%$ & $\mathbf{F}$ & $\%$ \\
\hline Male & 311 & 18.8 & 169 & 10.2 \\
\hline Female & 700 & 42.4 & 470 & 28.5 \\
\hline
\end{tabular}

Table (3) Frequencies distribution for the study sample in respect to their year of study $\left(\mathrm{No}_{\mathbf{0}}=110\right)$.

\begin{tabular}{|l|c|c|c|c|}
\hline \multirow{2}{*}{} & \multicolumn{2}{|c|}{ Yes } & \multicolumn{2}{c|}{ No } \\
\cline { 2 - 5 } & F & \% & F & \% \\
\hline First Year & 265 & 16.1 & 155 & 9.4 \\
\hline Second Year & 317 & 19.2 & 223 & 13.5 \\
\hline Third Year & 164 & 9.9 & 121 & 7.3 \\
\hline Fourth Year & 265 & 16.1 & 140 & 8.5 \\
\hline
\end{tabular}

Chi-Sq. $=6.713, \mathrm{DF}=3, \mathrm{P}-$ Value $=0.082$

\section{DISCUSSION}

The demographical characteristics of the study sample are shown in Figure (1). About (110) students participated in this study, this sample consisted of (32) male students and (78) female students. The highest number of participants are from second year (36) students, then (28) participants from first year, then (27) students from fourth year, and the lowest number of participants are from the third year about (19) students.

The results of the study showed that (Table 1) a high percentage $(85.5 \%)$ of the students stated that they didn't study about this subject. This means that there is no care about this subject in studying curriculums at the college.

Pipkin, (2011) reported that it was surprising to find that as who have family members or close friends with autism did not show significantly more knowledge about autism than those who do not. It is surprising that nursing students who had lectures specific to autism did not score higher on this questionnaire measuring knowledge about autism. As nursing students who answered "Yes" to having lectures specific to autism also scored similarly to PA students who denied having such lectures. This may be due to the small sample size of nursing students (50), or because the nursing students who responded may have interest in autism, and therefore, would have more general knowledge about autism.

According to the question " Do you think that parents' careless leads to Autistic disorder?", the results of the study showed that $(87.3 \%)$ of the participants answered positively about this point.This result is confirmed by a study conducted by Shabib (2008), stated that poor relationship between parents during pregnancy then neglecting care of their child is an essential cause for Autistic disorder.

According to the item " Autism could be associated with low communication.", the results of the study showed that $(96.4 \%)$ of the participants answered positively about this point. This finding was confirmed by Imran and others (2011) as they reported that $(95.1 \%)$ of participants appear to have a similar impression of the disorder as represented by the social deficits, communication difficulties and restricted interests demonstrated by children with Autism.

According to the item " Autistic characteristics appear before the third years age.", the results of the study showed that $(58.4 \%)$ of the participants answered positively about this point, while $(41.8 \%)$ of the 
participants answered negatively about this point. This indicates that the students are not sure about the age that autistic characteristics appear.

Imran and others (2011) reported that The American Academy of Pediatrics recommends that children be screened on a regular basis to detect any problems in their development, social skills and daily activities, which increases the chances of successful treatment and reduces the negative effects of the disease if detected. If the doctor detects any abnormalities or delays in developmental development for the child, the child is referred to a pediatric specialist, a psychiatrist (especially a child psychiatrist), or a psychotherapist. The doctor performs many psychological and medical tests for the child. The doctor begins an intensive examination of the patient's developmental and developmental history, general blood and urine tests and other medical examinations. Radiology tests are usually performed, especially in the case of seizures. Chromosomes are also examined. Some chromosomal diseases, such as Fragile X Syndrome, which are somewhat associated with the disease, are not autistic, but most autistic patients do not exhibit any chromosomal or somatic disorders. Sometimes, doctors check the level of lead in the blood, especially for children living in an environment exposed to this heavy metal, which may cause symptoms of autism.

The frequencies distribution for the study sample in respect to their gender is shown in table (2). The male and female students answered with "Yes" about (18.8\%) and (42.4\%) respectively. While they answered with "No" about (10.2\%) and (28.5\%) respectively.

The results of the current study need to be interpreted in light of several limitations since most participants were females. This is important because attitudes may differ between genders. While some studies have found no gender difference in attitudes toward people with disabilities (Tervo, Palmer, andRedinius, 2004), others found that women held more positive attitudes (Panek andJungers, 2008; Perry, et al., 2008). This may be explained in terms of the common perception of women as caregivers (Lemos, et al., 2003). This difference is important from a professional preparation perspective.

Yasar andCronin (2014) stated that the second limitation of their study is the reflection of gender in the field of education. Onehundred-thirty-four (24.3\%) male, and 417 (75.7\%) female College of Education students participated in the study. More female students were represented in the study; therefore, the results of the study may change depending on the participants' gender. Based on this sample, patterns of male/female attitudes and knowledge cannot be determined.

The frequencies distribution for the study sample in respect to their year of study is shown in table (3). The highest percentage of participants who answered with "Yes" are from second year (19.2\%) while the lowest percentage is $(9.9 \%)$ from the third year. The highest percentage of participants who answered with "No" are from second year (13.5\%) while the lowest percentage is $(7.3 \%)$ from the third year. This indicates that there was no difference in the level of knowledge between first year and fourth year nursing students concerning Autistic disorder.

A study by Shah (2001), focused on the knowledge of autism in medical students. His study found that there was no difference in the level of knowledge between first year and fourth year medical students concerning the treatment and prognosis of patients with autism. Both groups of students had the same amount of knowledge about the symptoms and diagnosis of autism. This study notes that these discrepancies in the knowledge of medical students needs to be addressed so that ASD's can be more effectively diagnosed and treated.

\section{CONCLUSIONS}

Depending on the results of this study, some conclusions are set: The study showed that there is no care about this subject in studying curriculums at the college. The students (sample of the study) are not sure about the age that autistic characteristics appear. Most of the sample of this study don't know if there are any health care centers in Mosul city for Autistic disorder. Finally, the study showed that there was no difference in the level of knowledge between first year and fourth year nursing students concerning Autistic disorder.

\section{RECOMMENDATIONS}

Depending on the results of this study, the following recommendations are set: More attention should be paid about this subject in studying curriculums at the college. Then awareness about Autistics disorder need to be improved among students and parents. Finally, nursing students have to make some visits to Autistics health care centers to increase their knowledge about signs and symptoms, and to be familiar to this disorder. 


\section{REFER'ENCES}

Adams, J.B.; Edelson, S.M.; Grandin, T.; and Rimland,B. (2004). Advice for Parents of Young Autistic Children. Center for The Study of Autism. Available:www. autism. Org. Aaccessed on [2007, 10 February].

Autism Society of America. Living with Autism. http://www.autismsociety. Available: org/site/ PageServer ? pagename= about_ whatis_factsstats [2007, 10 , February].

Baron-Cohen, S. (2005). Autism, in Hopkins, B. The Cambridge Encyclopedia of Child Development. Cambridge: Cambridge University Press. P.p.398 - 401.

Blair, D.C. (2002). Knowledge management: Hype, Hope or Help?, Journal of the American Society for Information Science and Technology. (53, 12). P.p.1019-1028.

Bregman, J.D. (2005). Definitions and Characteristics of the Spectrum. 3-46. In Zager, D. Autism Spectrum Disorders: Identification, Education, and Treatment. $\left({ }^{\text {rd }} \mathrm{ed}\right)$. London: Lawrence Erlbaum Associates Publishers.

Gillberg,C. andColeman, M. (2000). The Biology of the Autistic Syndromes. $\left(3^{\text {rd }} \mathrm{Ed}\right.$. ). London: Mac Keith Press.

Imran, N. (2011). A survey of Autism knowledge and attitudes among the healthcare professionals in Lahore, Pakistan. BMC Pediatrics. 11. P.p.107.

John Wiley and Sons. (2004). Definition of assessment of student learning from Assessment Clear and Simple: A Practical Guide for Institutions, Departments and General Education by Barbara E. Walvoord. P.p. 2-3.

Lemos, K., Suls, J., Jenson, M., Lounsbury, P., andGordon, E.E.I. (2003). How do female and male cardiac patients and their spouses share responsibilities after discharge from the hospital?. Annals of Behavioral Medicine. 25. P.p.8-15.

Mandelbaum, D.E., Stevens, M., Rosenberg, E., Wiznitzer, M.,Steinschneider, M., Filipek, P., andRapin, I. (2006). Sensorimotor performance in school-age children with autism, developmental language disorder, or low IQ. Developmental Medicine and Child Neurology. 48(1). P.p. 33-39.

Panek, P.E., and Jungers, M.K. (2008). Effects of age, gender, and causality on perceptions of persons with mental retardation. Research in Developmental Disabilities. 29. P.p. 125-132.

Parahoo, K. (2006). Nursing research principles process and issue. ( $2^{\text {nd }}$ ed.). China: Palgrave Macmillan.P.p.475-476.

Perry, T.L., Conner, A., and Shelar, D. (2008). Recreation student attitudes towards persons with disabilities: Considerations for future service delivery. Journal of Hospitality, Leisure, Sport andTourism Education.7(2). P.p.4-14.

Piek, J.P. and Dyck, M.J. (2004). Sensory-motor deficits in children with developmental coordination disorder, attention deficit hyperactivity disorder and autistic disorder. Human Movement Science. 23(3-4). P.p. 475-488.

Pipkin, L. Margaret. (2011). Physician Assistants' Knowledge and Attitudes Regarding Autism. University of Toledo. P.p. 15-16.

Shabib, A. Jasib. (2008). Psychological, Social and Mental Characteristics of Children with Autistic Disorder from parents' Point of View. A thesis submitted to British Academic for open teaching, Department of Psychology. P.p. 18-20.

Shah, K. (2001). What do medical students know about autism?. Autism. 5(2). P.p.127-133.

Stahmer, A.C., Collings, N.M., andPalinkas, L.A. (2005). Early intervention practices for children with autism: Descriptions form community providers. Focus on Autism and Other Developmental Disabilities.20. P.p. 66-79.

Taylor, B. (2006). Vaccines and the changing epidemiology of autism. Child: care, health and development. 32(5). P.p.511519.

Tervo, R.C., Palmer, G., and Redinius, P. Health professional student attitudes towards people with disability. Clinical Rehabilitation, 2004. 18, 908-915.

The National Autistic Society. Available: http://www.nas.org.uk [2007, 10 February]

VanBergeijk, E., Klin, A., and Volkmar, F. (2008). Supporting more able students on the autism spectrum: College and beyond. Journal of Autism and Developmental Disorders.38. P.p.1359-1370.

Zander, E. (2005). An introduction to autism. AUTISMFORUM Handikapp and Habilitering. www.autismforum.se, autism forum@sll.se. P. 3. 